\title{
EL URBANISMO POPULAR EN MÉXICO. ELEMENTOS PARA UNA HISTORIA PENDIENTE.
}

\author{
INFORMAL URBANISM IN MEXICO. \\ ELEMENTS FOR A MISSING HISTORY.
}

v. 9, n. 1 [15]

jan/abr (2017)

Dossiê "Villas Miseria, Favelas y Asentamientos: nuevas rutas en Historia Urbana"
Héctor Quiroz Rothe/Erika Alcántar García

UNAM, Posgrado en Urbanismo quiroz.urbanismo@gmail.com; erika.alcantarg@gmail.com

\section{Resumen}

En este trabajo se ofrece un resumen sobre las fuentes, temas y enfoques para la construcción de una historia del urbanismo popular, a partir del caso de la ciudad de México. Se trata de una propuesta que responde a un notable vacío dentro de la historiografía local, respecto a un proceso que explica el origen y conformación de la mayor parte del tejido socioespacial de las ciudades mexicanas contemporáneas. El documento se apoya en los resultados del trabajo de investigación documental y en campo realizado por los autores como integrantes del seminario de historia del urbanismo popular del Posgrado en Urbanismo de la Universidad Nacional Autónoma de México.

\section{Palabras clave}

Historia contemporánea de México. Historiografía del urbanismo. Urbanismo popular en la ciudad de México.

\section{Abstract}

This paper presents a summary of the sources, topics, and approaches to build a history of informal urbanism, focusing in the case of Mexico City. It offers an explanation to the striking gap in local historiography concerning the origin and evolution of a greater part of the urban and social tissue of Mexican contemporary cities. This document it's supported on documentary and field research realized by the authors and nourished through the debates in the History of Informal Urbanism Seminar organized by the City Planning Postgraduate Studies Program of the National Autonomous University in Mexico.

\section{Key words}




\section{Introducción}

Los procesos de urbanización protagonizados por la población de escasos recursos han sido una constante a lo largo del siglo XX en México y América latina. En este país, los barrios de origen irregular, construidos de forma progresiva mediante la participación directa de sus propios habitantes, representan más del $50 \%$ de las áreas urbanizadas actuales. ${ }^{1} \mathrm{~A}$ pesar de la importancia cuantitativa y cualitativa de este proceso para la comprensión del fenómeno urbano contemporáneo, consideramos que ha sido un tema relegado en la historiografía regional.

En este trabajo se revisarán algunas referencias bibliográficas básicas para obtener un panorama de la historia local del urbanismo popular focalizado en el caso de la ciudad de México, y al mismo tiempo identificar los principales enfoques en su estudio, así como los vacíos de información desde la perspectiva de la historia.

En un segundo apartado, se aportan datos y se proponen criterios de análisis, derivados de la investigación documental y de campo realizada por los autores y enriquecida con el intercambio que se ha realizado dentro del seminario de historia del urbanismo popular, con el fin de complementar el estudio histórico del urbanismo popular en la ciudad de México.

Finalmente, se realiza una reflexión sobre los enfoques, tendencias y ausencias en la historiografía local de este campo de conocimiento específico y trascendental para comprender la organización y funcionamiento de las ciudades mexicanas contemporáneas.

\section{Notas sobre las fuentes para la historia del urbanismo popular en la ciudad de México}

La vertiente hegemónica de la historia de las ciudades ha sido la de la arquitectura, la cual ha privilegiado-y legitimado-una serie de fuentes como el espacio construido, planos, escritos y teorías de renombrados arquitectos.

A partir de los años sesenta del siglo pasado los profesionales de la disciplina histórica comenzaron a estudiar los orígenes de las ciudades industriales, pues en regiones como la latinoamericana estaba teniendo lugar un proceso de urbanización de carácter popular explosivo y acelerado. Estos estudios con una perspectiva histórica se vieron como vía para comprender y explicar lo que había sucedido en occidente a partir de los procesos de industrialización y

${ }^{154 \%}$ de la superficie urbanizada de la zona metropolitana de la ciudad de México corresponde a colonias populares de origen informal, de acuerdo a los datos generados por Cenvi y publicados en Garza Gustavo (2000). Recientemente Emilio Duhau y Angela Giglia (2008) exploran seis tipos de ciudad o fragmentos que conforman la estructura metropolitana, entre los cuales se incluyen también las colonias populares (autoconstruidas). 
urbanización a lo largo del siglo XIX y principios del siglo XX. Particularmente los ingleses como John Dyos y Sidney G. Checkland contribuyeron a esta serie de trabajos desde una perspectiva crítica y analítica (MIRANDA, 2012).

En México la perspectiva de la explicación histórica de las ciudades-o historia urbanaes relativamente reciente. ${ }^{2}$ Entrados los años ochenta comenzaron a salir a la luz una serie de interpretaciones integradoras del fenómeno a nivel ciudad, apoyadas en una perspectiva histórica. Una de las aportaciones a este campo de la historiografía son las propuestas de Sergio Miranda, quien a partir de la revisión de la historia urbana inglesa y francesa propone a la urbanización como una vía de análisis para incorporar al espacio dentro de los estudios históricos (MIRANDA, 2012). Pero quienes han atendido esta urgencia son los profesionales de otras disciplinas.

A continuación presentamos algunos trabajos que han intentado abarcar e interpretar el complejo proceso de urbanización popular a lo largo del siglo XX de la ciudad de México. Estos datos se presentan en orden cronológico de acuerdo al periodo de estudio en el que se concentran.

En primer lugar se encuentra el texto de Maria Soledad Cruz ${ }^{3}$ Crecimiento urbano $y$ procesos sociales en el Distrito Federal (1920-1928) (CRUZ, s/a) en donde estudia cómo se articuló el proceso de recomposición social a través de la concertación de alianzas entre los grupos revolucionarios y lo sectores populares, dentro del proceso general de la construcción del Estado posrevolucionario.

En su estudio, la ciudad aparece como el espacio de la confrontación política, en donde surgen numerosos sectores con distintos objetivos y demandas. Estas demandas en los sectores populares y de trabajadores eran concretas, y se tradujeron en espacios para la vivienda. Así, su libro se estructura de manera que en un primer momento se explica el crecimiento de la ciudad en términos demográficos, para después abarcar el crecimiento físico de la urbe y los procesos que contribuyeron a su expansión. Pero particularmente el cuarto capítulo se concentra en la problemática de los tipos de vivienda para distintos sectores económicos en la ciudad de México: clases medias, burócratas y obreros (CRUZ, s/a).

El segundo de estos trabajos es el del economista y sociólogo Manuel Perló, quien revisó el periodo cardenista desde una visión estructural, fundada en la sociología crítica de la segunda mitad del siglo pasado. En su libro Estado, vivienda y estructura urbana en el cardenismo (1981),

\footnotetext{
2 Si bien se pueden citar los primeros intentos de aproximarse al pasado de las urbes mexicanas a finales de los años setenta con las iniciativas de Alejandra Moreno Toscano, sus seminarios e investigaciones revisaban casos de estudio: la historia de localidades e hitos de ciudades mexicanas (RESEARCH IN PROGRESS ON URBAN HISTORY, 1991).

3 También se puede hacer mención de "La institucionalización de las colonias populares y la política urbana en la ciudad de México (1940-1946)", que salió a la luz en 1989 en la revista del departamento de sociología de la Universidad Autónoma Metropolitana. En dicho artículo, los autores esgrimían que durante los años setenta del siglo pasado, algunos intelectuales habían calificado de "inéditas" una serie de medidas que parecían replantear el papel del Estado debido a su alto nivel de intervención en el desarrollo urbano y el ordenamiento territorial.
} 
el autor reconoce a este periodo de la historia del país, pero particularmente de la Ciudad de México, como determinante en cuanto al tipo de urbanización que se consolidó y dio forma a la estructura urbana, así como a sus formas sociales en el espacio.

El autor estudia una serie de transformaciones urbanas concretas que tuvieron lugar durante la administración de Lázaro Cárdenas, de las cuales algunas son reparto de tierras ejidales y su posterior urbanización, la migración masiva que comienza a finales de este periodo, la invasión de terrenos de propiedad privada, la expropiación de los mismos para la conformación de colonias proletarias, así como la gran inversión en materia de infraestructura y servicios urbanos, fenómenos que son parte de esa primera historia del urbanismo popular, íntimamente ligada a la construcción de un Estado Posrevolucionario con miras a estructurar una base económica fundada en la industrialización.

En la segunda parte de este trabajo es donde se dedica más puntualmente al tema de las formas de habitación popular, en donde revisa los "procesos urbanos del cardenismo". Lo relevante de esta aproximación pionera a la historia del urbanismo popular, es que el autor ya advierte a este periodo como el de germinación de un proceso de urbanización característico de la capital mexicana, a partir de las relaciones que estableció el Estado con los sectores populares y trabajadores, así como con su inserción dentro del proceso de inversión económica en la principal urbe del país (PERLÓ, 1981, p. 12).

El siguiente texto que se puede nombrar dentro de esta perspectiva histórica, interpretativa y abarcadora del conjunto de la ciudad de México es el libro de Cristina Sánchez Mejorada, Rezagos de la modernidad. Memorias de una ciudad presente (SÁNCHEZ MEJORADA, 2005). Este trabajo se centra en distintas dimensiones de la política urbana entre los años 1940 y 1952, periodo de expansión urbana acelerada al que ya se ha hecho referencia, pero ahora hasta el periodo presidencial de Miguel Alemán Valdés. Allí revisa la creación de las instituciones posteriores a la creación del Departamento del Distrito Federal, el estado financiero de la capital, los intentos de planificación urbana en esas décadas y los actores que intervenían en ello, la problemática del transporte a partir de sus problemas internos, y la política de vivienda y los tipos de poblamiento.

Es en este capítulo donde realiza sus contribuciones a la historia de la urbanización popular de la ciudad. Sobre todo destaca la capacidad analítica con la que presenta los distintos tipos de poblamiento a partir de sus características: los tugurios y las ciudades perdidas, las Unidades Habitacionales y las colonias para trabajadores, fraccionamientos, colonias proletarias y la vivienda en renta (SÁNCHEZ-MEJORADA, 2005, p. 181-224). Todos estos tipos de poblamiento que conviven en la ciudad de estos años pueden ubicarse dentro de los márgenes de lo que se ha denominado urbanismo popular.

Este trabajo destaca también por su técnica de reconstrucción de casos mediante documentos de archivo. A excepción de los tugurios, ciudades perdidas y las viviendas en renta, que estaban sobre todo referidas a la zona centro de la ciudad y no eran viviendas nuevas, en 
todos los demás tipos se narra la evolución de casos representativos de esa forma de poblamiento.

Otra investigación con una perspectiva histórica de la ciudad es el clásico El Leviatán urbano de Diane Davis (DAVIS, 1999), quien hace una historia de la ciudad de México en el siglo XX, también a través de la política urbana, pero sobre todo desde una perspectiva políticoadministrativa.

Hay que señalar que las colonias populares u otros componentes del urbanismo popular no son el tema central en ninguno de los capítulos que conforman su afamado libro, en donde el eje narrativo es el desarrollo de conflictos entre actores emergentes en la política urbana a partir de los distintos intereses en los procesos de urbanización. Sin embargo, las colonias populares son tratadas cada vez que se hace referencia a la expansión de la ciudad, particularmente en el periodo de Ernesto Uruchurtu (1952-1966) (Davis, 1999, p. 229-232). En este texto también se hace referencia dentro de la misma administración a algunas de las medidas de desalojo de los entonces nombrados "paracaidistas", y de algunos casos de reubicación del mismo regente, con los cuales conciliaba las demandas de sectores de trabajadores y clases medias (Davis, 1999, p. 253-254).

Un texto más que contribuye a dibujar el panorama general de la ciudad de México durante el siglo XX es el libro de Peter Ward, México: una megaciudad (1991). Hay que aclarar que no todo el trabajo intenta hacer una explicación histórica de las distintas dimensiones de la ciudad, pero sí el que explica la evolución de sus formas de urbanización. En el capítulo II, "Crecimiento urbano y apropiación del espacio: de plaza a suburbio y a megaciudad", el autor explica la evolución demográfica, espacial y las dinámicas de poblamiento que tuvieron lugar en la ciudad de México desde principios del siglo XX hasta los años noventa, momento en que escribe el autor.

Nos interesa mencionar particularmente este capítulo de Ward porque en él introduce análisis demográficos y de la geografía urbana para explicar la evolución de la ciudad en el siglo XX. Así, explica la expansión de la periferia capitalina entre los años sesenta y setenta mediante la migración intraurbana, la segregación socioespacial y la forma en que se desenvolvían los mercados de vivienda para los distintos sectores de la población, concentrándose especialmente en el centro deteriorado cuya oferta habitacional era de cuartos en alquiler y en la periferia de las colonias populares (WARD, 1991).

Aquí debemos hacer mención de otra incipiente forma de aproximarse al estudio del Urbanismo Popular. Nos referimos a la historiografía. Ésta se entiende como el estudio de la escritura de la historia, y desde la institucionalización de la disciplina histórica, se refiere sobre todo a los profesionales, es decir, los historiadores, que se dedican al análisis de los objetivos, metodologías empleadas y la estructuración y construcción del discurso histórico.

Recientemente ha habido algunos esfuerzos por evidenciar que existe una investigación significativa en torno al urbanismo popular. Por mencionar sólo una de ellas se encuentra la 
propuesta de Priscilla Connolly, quien en su ponencia "La ciudad y el hábitat popular: Paradigma latinoamericano" (2011), explica dos procesos de la investigación acerca del estudio del Urbanismo Popular. El primero tiene que ver con el fenómeno de la investigación misma a partir de los planos ontológicos, epistémicos y metodológicos. De esta manera, la autora advierte que hay una forma de aproximarse a los fenómenos, basada en las intenciones individuales, políticas y profesionales de los investigadores, las cuales se articulan con el uso de conceptos y de teorías. Esto ha dado como resultado el segundo fenómeno que explica la autora, que es el de la constitución de un "Paradigma latinoamericano" de investigación. Éste tiene dos momentos a considerar: de 1970 a 1990 y de 1990 a la actualidad. El primer periodo de tiempo hace alusión a las investigaciones paralelas a la emergencia de la urbanización popular en América Latina y su articulación con las luchas políticas. En el segundo momento, se analiza con cierta distancia la explosión del proceso y hace mucho más énfasis en las cuestiones interpretativas.

Por último, se encuentra un texto de difícil clasificación por situarse entre el testimonio y la interpretación histórica. Nos referimos a La chispa. Orígenes del Movimiento Urbano Popular en el Valle de México de Pedro Moctezuma Barragán (2012) economista que presenció y participó en varios casos de urbanización popular y lucha por la vivienda en la periferia de la Ciudad de México. $^{4}$

Su historia es contada en primera persona, con una narración casi literaria, más cercana a la crónica que a una investigación de carácter historiográfico. Pero en ella se advierte una amplia y ambiciosa periodización del Movimiento Urbano Popular a través de los casos más emblemáticos de organización de colonos en la ciudad. A partir del caso de San Miguel Teotongo explica los orígenes de muchas colonias en la capital mexicana a partir de la migración o la ocupación organizada mediante la cooptación del partido hegemónico. Por otro lado, presenta a los distintos actores que emergieron a lo largo del proceso como los fraccionadores, los líderes, los "invasores", las familias en busca de vivienda accesible a su capacidad de compra, etc. Asimismo, presenta la serie de conflictos en torno al proceso de urbanización popular como los fraudes, la gestión de los servicios, las transacciones de compra-venta de lotes. Denuncia las distintas formas de coerción que existían para amedrentar a los grupos organizados por la vivienda como la creación de grupos de pistoleros que exigían el pago de impuestos ilegítimos, así como el contubernio de autoridades locales y los grupos de fraccionadores que buscaban beneficiarse de la necesidad de servicios y vivienda de los sectores populares.

De esta manera, el texto resulta una etnografía del proceso de urbanización popular y una crónica puntual de la evolución política y los objetivos del Movimiento Urbano Popular, de su institucionalización en los años ochenta, de la vinculación con otros grupos para su

\footnotetext{
4 También se puede hacer mención de su artículo "El movimiento urbano popular" de 1984, en donde intenta hacer un balance de las conquistas del Movimiento a lo largo de sus primeros años de existencia. Aquí hacemos referencia a La Chispa... por tratarse de un texto con una intención interpretativa además de analítica. (Barragán, 1984).
} 
fortalecimiento, de sus enfrentamientos internos, y de experiencias de vanguardia en las cooperativas de vivienda como CANANEA y el predio El Molino.

Si bien el libro de Moctezuma Barragán puede ser considerado un testimonio, éste resulta ineludible a la hora de hablar de una historiografía del urbanismo popular, pues en él se presenta un balance general del proceso de organización política, una explicación acerca del contexto político, económico y social en la ciudad de México de esos años, y, al mismo tiempo, una selección de casos y una interpretación explícitamente subjetiva del proceso de urbanización popular.

Esta serie de investigaciones han contribuido a evidenciar la complejidad política y socioespacial de la urbanización popular a lo largo del siglo XX. En esa medida estas aproximaciones pueden ser consideradas indispensables, pues a pesar de que existe una abundante literatura sobre los procesos autogestivos de urbanización y ocupación del territorio, éstos carecen de una interpretación histórica. Cabe recalcar que han sido otras ciencias sociales más familiarizadas con el nivel de análisis espacial, como la sociología y la economía, las que se han encargado de historiar el urbanismo popular en sus distintas etapas. Por su parte, queda como uno de los grandes pendientes dentro de la agenda de la historia urbana, la aportación de los urbanistas y los historiadores a una visión integradora del proceso de urbanización popular y de la ciudad en su conjunto.

La irregularidad asociada al origen de muchas colonias populares limita, según el caso, la existencia de fuentes documentales oficiales para el estudio de su evolución. La investigación histórica sobre este fenómeno dispone de otras fuentes que exigen un tratamiento específico desde la teoría y la metodología. En primer lugar consideramos las fuentes orales. Dentro del proyecto de investigación Historia del urbanismo popular hemos realizado una serie de entrevistas con líderes y representantes de comunidades emblemáticas de la producción autogestiva de vivienda, equipamientos y servicios urbanos. La información derivada de estas fuentes ha enriquecido considerablemente el estudio del fenómeno y se refleja a lo largo de todo el contenido de nuestro trabajo. De igual manera hemos recurrido a líderes de organizaciones no gubernamentales que han jugado un papel muy importante en la consolidación de proyectos comunitarios. Un ejemplo notable es el arquitecto Enrique Ortiz Flores, miembro desde 1965 de la ONG Copevi, fundador en 1976 de la Coalición Hábitat Internacional (HIC por sus siglas en inglés) de la cual fue secretario general internacional y presidente. Asesor y funcionario del gobierno federal en el sexenio 1982-88, concretamente en el Fondo nacional para las habitaciones populares (Fonhapo), coautor del primer programa nacional de vivienda y reconocido activista por el derecho a la vivienda, defensor de la producción social del hábitat y promotor del derecho a la ciudad.

A través de los encuentros organizados en el seno del Seminario de Historia del Urbanismo Popular se han podido confirmar la existencia de archivos que resguardan testimonios y documentos diversos (textos, fotográficos, audiovisuales) que si bien no cuentan con una 
clasificación rigurosa en todos los casos constituyen referencias muy valiosas para nuestro proyecto. Es el caso de los centro de documentación de ONGs como la Coalición Hábitat Internacional, Copevi, Casa y ciudad, Fosovi o Cenvi. También se han identificado archivos personales o colectivos resguardados por organizaciones populares como la Unión Popular Revolucionaria Emiliano Zapata, o los vecinos organizados de El Molino, el Campamento 2 de octubre, la Cooperativa Palo Alto o el Pedregal de Santo Domingo (en el Centro de Artes y Oficios Escuelita Emiliano Zapata) por mencionar algunos ejemplos de muchos que deben de existir en el anonimato.

Respecto a los documentos audiovisuales (cine y vídeo) el catálogo documental de la Filmoteca de la UNAM que resguarda material producido por dependencias del gobierno; por otro lado el Centro Universitario de Estudios Cinematográficos cuenta con un archivo de los trabajos realizados por sus estudiantes desde la década de 1960, entre los cuales se encuentran documentales (en distintos formatos) sobre problemas sociales y conflictos vinculados con el origen y evolución de los asentamientos irregulares y colonias populares, en espera de una relectura desde la historia. Un caso excepcional es el documental de Gustavo Alatriste $Q R R$. Quién resulte responsable (México 1970) el cual describe en el estilo del cinema verité los paisajes y habitantes de Ciudad Nezahualcoytl.

En esta producción el realizador documenta con cámara la vida cotidiana de este municipio de la periferia de la Ciudad de México. Con micrófono en mano preguntaba a los colonos acerca de sus condiciones de vida, de sus viviendas, de las largas jornadas en el transporte escaso y de mala calidad que les llegaba (Quien resulte... 1970). Éste, como otros documentales de este tipo, el día de hoy son una fuente de acceso privilegiada al proceso del urbanismo popular, dado su carácter audiovisual: la imagen en movimiento puede contribuir enormemente al estudio e interpretación del proceso.

\section{Avances y consensos en la investigación}

En los años 2012 y 2014 se convocaron un par de encuentros académicos con formato de seminario, para reflexionar sobre la temática del urbanismo popular desde una perspectiva histórica. La iniciativa surgió de un grupo de colegas $^{5}$ con un perfil multidisciplinario que ha enriquecido una discusión académica en la que existen coincidencias respecto a considerar que el urbanismo popular ha determinado el tejido socioespacial de las ciudades mexicanas contemporáneas -y por extensión latinoamericanas- en términos cuantitativos y cualitativos. Consideramos igualmente que las condiciones de informalidad, irregularidad, progresividad, espontaneidad, que lo caracterizan no son una excepción frente a la supuesta racionalidad del

${ }^{5}$ Encabezado por Priscilla Conolly, Angela Giglia, Sergio Miranda, María de Lourdes García y Héctor Quiroz, quienes procedemos de formaciones variadas que incluyen la arquitectura, la antropología, la historia, el urbanismo, la sociología y la geografía. 
urbanismo institucional y académico. Se trata de otro orden, no del desorden, considerado como la condición que explica este fenómeno social y espacial desde la perspectiva hegemónica.

Este proyecto retoma muchas ideas de la crítica que planteaba la arquitectura social en los años setenta en América latina; ${ }^{6}$ cuando esta región estaba marcada por las luchas sociales frente al autoritarismo estatal, la urbanización acelerada y la convergencia de ideologías aparentemente antagónicas, desde la izquierda radical a la teología de la liberación. En este sentido, la contribución principal del seminario ha sido el diálogo interdisciplinario y una mirada renovada por la distancia respecto a los acontecimientos y debates que han marcado el análisis de este fenómeno durante las últimas décadas.

De forma paralela al seminario se ha venido desarrollando un proyecto de investigación enfocado a documentar los procesos de construcción de la ciudad protagonizados por la población de menores recursos en la ciudad de México, durante la segunda mitad del siglo pasado. Con el fin de identificar los agentes, estrategias y recursos formales e informales que derivaron en entornos construidos diversos, pero que denominamos genéricamente colonias populares, se han realizado entrevistas con expertos académicos y líderes de organizaciones sociales vinculadas con la producción social del hábitat. ${ }^{7}$

A continuación se presenta un resumen de los principales planteamientos derivados de esta investigación y del diálogo multidisciplinario realizado dentro del seminario, organizados en cuatro temáticas específicas de la historia del urbanismo popular:

- Periodización

- Tipologías

- Agentes y discursos

- Fuentes para su estudio

Sobre una periodización de la historia del urbanismo popular en México

En un espacio temporal que abarca el siglo $X X$, se identifican al menos cuatro momentos:

1) Una etapa primigenia; a la vuelta del siglo XIX y hasta el periodo revolucionario (19101921 ) el hábitat popular urbano se reduce básicamente a la tipología de las vecindades ${ }^{8}$ y algunas experiencias puntuales de vivienda obrera patrocinadas por empresarios filántropos equiparables a proyectos realizados en países industrializados. El contexto socioeconómico corresponde con una industrialización incipiente, en el que la localización

\footnotetext{
6 No hay que perder de vista que en estos años arquitectos como John Turner están difundiendo los métodos de autoconstrucción latinoamericana; por otro lado, estaba en auge la teología de la liberación en la región.

7 El material obtenido fue editado en tres audiovisuales en formato dvd (Testimonios... 2013), (Testimonios... 2014), (Interiores... 2015). Todos realizados por Héctor Quiroz Rothe. Contacto quiroz.urbanismo@gmail.com

8 Viviendas de alquiler colectivas, consistentes en cuartos redondos con servicios compartidos, concentradas en la ciudad central
} 
de las fábricas depende de la proximidad de fuentes de energía (hidroeléctrica) y de los proveedores materias primas, frecuentemente en espacios periféricos de los núcleos urbanos existentes.

2) Un periodo de experimentación social (posrevolucionario) en las décadas de 1920 y 1930. Aquí se ubican la construcción de los primeros conjuntos modernos de vivienda social auspiciados por el gobierno emanado de la Revolución. De forma paralela se promueve la construcción de colonias proletarias cuyo diseño respondía el proyecto social cardenista, el cual en el ámbito rural se manifestó en el reparto agrario masivo que dio lugar a la creación de numerosos ejidos ${ }^{9}$ que con el paso de los años se convertirían en una especie de reserva de suelo para la urbanización informal. Este periodo corresponde con el arranque de la transición demográfica.

3) Una etapa de crecimiento económico y urbanización acelerada (1945-1980). La industrialización por sustitución de importaciones, coincide con la transición demográfica y la expansión acelerada de las principales ciudades del país. En política se consolida el sistema del partido único ${ }^{10}$, que coopta todos los sectores sociales y reprime la disidencia. Dentro del aparato estatal se formalizaron los organismos encargados de la producción de vivienda social, que aunque se pretendía obrera, atendió al principio la demanda de funcionarios y empleados medios del gobierno. Posteriormente, en la década de los setenta, con la creación de fondos de vivienda para los trabajadores, esta oferta se diversificó para atender las necesidades de otros sectores sociales. ${ }^{11}$

En cualquier caso, ante la incapacidad de las instituciones estatales para satisfacer la demanda de suelo y vivienda, las familias de escasos recursos optaron por la ocupación de terrenos en la periferia urbana, dando lugar a asentamientos irregulares (sin servicios y de tenencia irregular). Durante estas décadas, el tratamiento de los asentamientos informales por parte de las autoridades, transitó entre la represión y la indiferencia, con lapsos de tolerancia, cooptación y manipulación con fines partidistas, e incluso momentos de apoyo y promoción. Este periodo culmina con la puesta en marcha de programas de apoyo a la organización de cooperativas de vivienda y a la autoconstrucción, subsidiados por las grandes instituciones de financiamiento y cooperación internacional. ${ }^{12}$

4) Crisis y proyecto neoliberal (1990-2015). La década pérdida fue el preámbulo para la implantación del modelo neoliberal basado en la desregulación de la economía y la

\footnotetext{
9 Lázaro Cárdenas, presidente de México entre 1934-1940. Durante su gobierno se implantó el primer plan de desarrollo nacional inspirado en la experiencia soviético. Se le recuerda por el impulso definitivo al reparto agrario, a las organizaciones obreras y por la nacionalización de la industria petrolera. Hasta la fecha sigue siendo una referencia histórica de la izquierda mexicana.

La propiedad ejidal era colectiva e inalienable (hasta las reformas constitucionales de 1994)

${ }^{10}$ El Partido Revolucionario Institucional que gobernó al país hasta el año 2000.

11 Nos referimos al Instituto del Fondo Nacional de Vivienda para los Trabajadores (Infonavit) y el Fondo de Vivienda de los Trabajadores del Estado (Fovisste).

12 El reconocimiento de la capacidad organizativa de los pobres urbanos para resolver el problema habitacional se formaliza durante la primera Conferencia sobre Hábitat, celebrada en Vancouver en 1976.
} 
privatización del sector paraestatal (industria y servicios). Coincide con el fin del crecimiento demográfico acelerado y la desconcentración de las actividades económicas en el territorio nacional. La producción de vivienda social queda en manos de grandes empresas constructoras de vastos conjuntos de vivienda de interés social en la periferia de las ciudades.

Cabe señalar que hasta la fecha persisten sectores de población que siguen recurriendo a la experiencia histórica de los asentamientos irregulares y los procesos autogestivos en sus versiones más perversas y virtuosas. Es decir, el clientelismo por un lado y las experiencias alternativas herederas del cooperativismo y la autogestión social por otro. Se trata de una evidencia contundente de la continuidad de procesos históricos y del arraigo de procedimientos políticos y económicos de la informalidad.

Sobre el origen, localización y tipologías del urbanismo popular

En el caso de la ciudad de México, los antecedentes de este fenómeno se pueden remontar a los barrios indígenas que quedaron excluidos de la traza española en el siglo XVI; aunque se acepta que es en el siglo XX cuando la urbanización popular se convierte en un proceso masivo y predominante dentro de la estructura de las ciudades mexicanas.

Desde una perspectiva morfológica, en la estructura metropolitana de la ciudad de México se pueden identificar claramente dos grandes sectores: un polígono al surponiente en donde se concentran prácticamente todas las colonias residenciales de la ciudad así como los distritos de negocios y las zonas comerciales más prestigiosas; y un polígono al nororiente en donde predomina la vivienda popular y la industria. Esta división funcional se originó por las diferencias topográficas y edafológicas del valle acentuadas por el proceso de desecación de los lagos sobre los que se asentó la metrópoli. ${ }^{13}$

Desde los tiempos coloniales, los barrios ubicados al oriente y al norte de la Plaza Mayor concentraron a los grupos de población menos privilegiados. Para reforzar su desprestigio, en este rumbo se establecieron el leprosario y el principal mercado de abasto popular; posteriormente en el siglo XIX se construyó el Gran Canal del Desagüe, la cárcel de Lecumberri y finalmente el aeropuerto. Ambientalmente eran los terrenos más insalubres por su cercanía con las aguas salobres del fondo de lago de Texcoco, convertido en un pantano cenagoso conforme avanzaba su desecación y al mismo tiempo los terrenos más propensos a las inundaciones cíclicas durante las temporadas de lluvias.

\footnotetext{
${ }^{13}$ La ciudad de México y su zona metropolitana se asienta en una cuenca endorreica ${ }^{13}$ cuyo fondo estuvo cubierto hasta el siglo XVI por un sistema de cinco lagos someros: Zumpango, Xaltocan, Texcoco, Xochimilco y Chalco que cubrían una superficie de $1500 \mathrm{~km} 2$. Los tres primeros de aguas salobres. Cabe destacar que dichos lagos fueron desapareciendo conforme el crecimiento de la ciudad, sobre todo en los albores del siglo XX.
} 
En contraste, al poniente de la Plaza Mayor, desde la refundación de la ciudad se instalaron los conventos de mayor alcurnia y prácticamente la totalidad de los palacios de la nobleza novohispana. Adicionalmente los acueductos que proveían de agua potable a la ciudad remataban en fuentes localizadas en este rumbo. En el siglo XIX, la expansión de la ciudad burguesa se organizó a partir del eje del Paseo de la Reforma (proyectado originalmente por el emperador Maximiliano en su breve Imperio de 1864-67). Precisamente, esta arteria conectaba el casco histórico de la ciudad con el Bosque de Chapultepec (en donde se localizó el palacio imperial y la residencia presidencial hasta 1940) y con los nuevos suburbios residenciales localizados preferentemente en los terrenos más elevados y salubres localizados al poniente $y$ al surponiente del valle. A lo largo del siglo del siglo $\mathrm{XX}$, el eje de Reforma tuvo varias ampliaciones que reforzaron esta tendencia.

Este es el origen de la marcada diferenciación que existe entre los fraccionamientos residenciales que predominan al surponiente del centro histórico y los barrios y colonias populares que fueron ocupando las tierras resecas del ex vaso del lago de Texcoco en dirección oriente y nororiente a lo largo del siglo XX.

Entre las cadenas montañosas que delimitan la cuenca sobre la que se asienta la ciudad, cabe distinguir las sierras de Las Cruces al poniente y el Ajusco al sur. La primera de ellas, por su proximidad con el núcleo histórico de la ciudad, fue urbanizada de forma temprana al iniciarse la expansión de la mancha urbana. En 1921, coincidiendo con la primera prolongación del Paseo de la Reforma, se construyó en sus laderas el fraccionamiento Lomas de Chapultepec considerado el primer suburbio moderno de la ciudad por su diseño adecuado a la circulación de automóviles particulares- a partir del cual se detonaría la aparición de otros asentamientos similares que explotaban las cualidades ambientales y paisajísticas de este territorio. El proceso no estuvo exento de la aparición de asentamientos irregulares en los terrenos menos aptos como los fondos de las cañadas y las laderas más accidentadas- ocupados en parte por las familias de los empleados domésticos y prestadores de servicios a la población de mayores ingresos. ${ }^{14}$ Esta mezcla que ha generado un paisaje urbano contrastante, y que resulta positiva socialmente, no existe en la periferia oriente en donde como ya hemos mencionado prevalece más bien una mezcla masiva y homogénea de colonias populares, conjuntos habitacionales de interés social y zonas industriales. ${ }^{15}$

Al interior del valle existen otros elementos orográficos como las sierras de Guadalupe y Santa Catarina, así como los cerros de la Estrella, del Judío, Chimalhuacán, Xico entre otros, cuyas las laderas fueron ocupadas exclusivamente por asentamientos precarios y colonias populares a partir de la segunda mitad del siglo pasado.

\footnotetext{
${ }^{14}$ Las laderas de la Sierra de las Cruces es un área rica en yacimientos de arena, cuya explotación a lo largo del siglo pasado propició la formación de campamentos de trabajadores que serían también el origen de muchas colonias precarias de la zona.

15 Como referencia señalamos las delegaciones Iztapalpa, Gustavo A Madero y los municipios de Nezahualcoyotl y Ecatepec que reúnen en conjunto una población de más de cinco millones de habitantes.
} 
Por último, al sur del valle se localiza el Pedregal de San Ángel, un paisaje de malpaís resultado de una erupción volcánica ocurrida hace dos mil años, que originalmente cubría una extensión de $70 \mathrm{~km} 2$, de los cuales hoy sólo se conservan 124 has dentro del campus de la Universidad Nacional (LOT; CAMARENA, 2009). Hasta el siglo XX fue una barrera natural para el crecimiento de la ciudad. A pesar de ser un sitio poco apto para la urbanización, fue ocupado a partir de la segunda mitad del siglo pasado indistintamente por exclusivos fraccionamientos residenciales (Jardínes del Pedregal) y asentamientos irregulares (Pedregal de Santo Domingo) que han uniformizado su accidentada topografía al integrarse a la mancha urbana.

Además de los elementos orográficos arriba descritos, consideramos que la desecación del sistema lacustre ha sido una condición determinante para explicar el origen y localización de las colonias populares irregulares. Este proceso inició en el siglo XVII y continúa hasta la fecha con el proyecto del drenaje profundo aun en construcción. De manera muy general, las tierras que emergieron de los lagos de agua dulce fueron ocupadas por haciendas y ranchos, los cuales en su momento fueron fraccionados para dar lugar a suburbios residenciales destinados a los sectores de ingresos medios y altos, caracterizados por la regularidad de la tenencia de la tierra, condición indispensable para el desarrollo del mercado formal de suelo y vivienda. ${ }^{16}$ En contraste, los terrenos que resultaron de la desecación de los lagos de aguas salobres permanecieron desocupados hasta que el crecimiento demográfico y la expansión urbana los convirtió en una reserva de suelo para cubrir las necesidades de la población de escasos recursos.

En cualquier caso, las barreras naturales que históricamente determinaron o condicionaron el crecimiento de la ciudad de México (lagos, laderas y pedregales) fueron superadas gracias al desarrollo reciente de la tecnología constructiva que ha permitido edificar en cualquier tipo de suelo y que fue apropiada tanto por los desarrolladores como por la población de escasos recursos organizada. En este sentido, las diferencias en las formas de urbanización -formal o informal- han estado determinadas sobre todo por el tipo de propiedad del suelo. La propiedad privada es una condición para el origen de fraccionamientos residenciales y parques industriales.

Por otra parte, las formas de propiedad colectiva (ejidal y comunal) fueron, al menos hasta la reforma de 1992, una condición asociada estrechamente al origen de asentamientos irregulares. Aunque se han dado casos de expropiación de ejidos para beneficiar a desarrolladores privados o bien construir conjuntos habitacionales financiados por el Estado. La condición de informalidad se puede extender a los terrenos de propiedad pública (federal) y a las zonas de conservación ecológica. Lo que explica el origen de numerosas colonias populares

\footnotetext{
16 Esa el caso emblemático de las haciendas de la Teja (colonias Cuauhtémoc y Anzures), de los Morales (colonia Polanco), de la Condesa (colonias Roma y Condesa) y de Narvarte (colonias Del Valle y Narvarte), entre otras, que fueron fraccionadas paulatinamente a partir desde el último tercio del siglo XIX y hacia comienzos de 1900 dando lugar a suburbios residenciales que terminarían consolidándose en el segundo cuarto del siglo pasado.
} 
de las delegaciones Iztapalapa, Xochimilco, Tlahuac o de los municipios de Chalco y Nezahualcoyotl.

\section{Tipologías del urbanismo popular}

Como hemos señalado, en las primeras etapas de la industrialización en México, los inmigrantes rurales cubrieron sus necesidades de alojamiento dentro de conjuntos de vivienda de alquiler concentradas principalmente en el caso histórico de la ciudad y conocidos localmente como vecindades. Las vecindades son edificaciones organizadas alrededor de patios y con servicios compartidos: baños, áreas de lavado, etc. con viviendas de tipo cuarto redondo. Los antecedentes de esta tipología constructiva se remontan a la época colonial. A finales del siglo XIX, cuando las clases acomodadas empezaron a abandonar el centro de la ciudad, sus viejas mansiones fueron subdivididas como vecindades. Paralelamente también se construyeron edificios ex profeso para este mismo uso en distintos rumbos de la ciudad como parte de negocios inmobiliarios antes de la llegada de los condominios y los edificios de departamentos. A mediados del siglo XX, la política de rentas congeladas marcó el destino de las vecindades que entraron en un proceso de deterioro por falta de mantenimiento de la edificación e instalaciones, que a su vez fomentó la expulsión hacia la periferia de aquellas familias que lograban obtener una vivienda en uno de los nuevos conjuntos habitacionales, pero sobre todo un lote en una colonia popular. De esta manera en las vecindades permanecieron o se incorporaron grupos de población cada vez más vulnerables: familias indígenas, ancianos, discapacitados (invidentes) quienes han aprovechado al máximo las ventajas de una localización residencial central como compensación de los inconvenientes derivados de su condición social o física.

En los años setenta surgieron grupos de inquilinos que luchaban por la permanencia en la ciudad central, oponiéndose proyectos de renovación urbana promovidos por las autoridades, acompañados de desalojos y reubicaciones en conjuntos habitacionales en la periferia. El terremoto de 1985, si bien afectó considerablemente la estructura de muchas de estas edificaciones; también exhibió el deterioro de las condiciones de vida de sus habitantes, dando lugar a un programa de reconstrucción que favoreció la permanencia de las familias de inquilinos en los barrios de la ciudad central.

De regreso en el tiempo, en la década de 1930 el gobierno federal promovió la formación de colonias proletarias para cubrir la demanda de la clase trabajadora en expansión. Dos ejemplos de esta tipología son la colonia Michoacana y el proyecto de la primera Unidad Santa Fe firmado por Hannes Meyer. En ambos casos existían consideraciones para preservar ciertos aspectos de la vivienda colectiva considerados virtuosos en la construcción de una sociedad que privilegiaba la la cooperación y solidaridad de sus miembros. ${ }^{17}$

\footnotetext{
17 Ver los artículos "¿De la arquitectura oficial al urbanismo popular" (QUIROZ, 2014) y "La colonia obrera Lomas de Becerra" de Claudia Zamorano y Georg Leidenberger (QUIROZ, 2014).
}

(c) Urbana: Rev. Eletrônica Cent. Interdiscip. Estud. Cid

Campinas (SP)

v.9, n.1[15] p.47-69

ISSN 1982-0569 
En esta misma época, se ubican las primeras iniciativas del gobierno para producir vivienda social, inspiradas en proyectos desarrollados por los representantes del movimiento moderno de la arquitectura en Europa. Ejemplos de este tipo de iniciativas son los conjuntos de San Jacinto, Santo Tomás (colonia Prohogar), la Unidad Modelo, la Unidad Esperanza o el conjunto SCOP. Se trata de un urbanismo para los pobres, que se sintetiza en el concepto de unidades habitacionales o conjuntos de vivienda social producidos por el Estado y que tuvieron su momento de máxima expansión entre las décadas de 1950 y 1980 . El denominador común de estos espacios urbanos es que fueron planificados y proyectados a través de una institución oficial con la participación directa de profesionales de la construcción, atendiendo un programa de necesidades preestablecido y generalmente siguiendo los criterios estéticos dominantes. Los conjuntos habitacionales constituyen la expresión más acabada de la concepción racionalista de la ciudad.

A mediados del siglo pasado se formalizaron dentro del aparato estatal dependencias dedicadas a la producción de vivienda social, que aunque se pretendía obrera, atendió básicamente la demanda de funcionarios y empleados medios del gobierno. El Conjunto Urbano Presidente Alemán inaugurado en $1949^{18}$, marcó el inicio de un periodo en la historia de esta forma de urbanización que se distingue por la participación de grandes nombres de la arquitectura nacional con un cuidado proceso de diseño que derivó en espacios privados y colectivos de gran calidad, con generosos espacios abiertos, equipamientos públicos integrados e instalaciones que habían permanecido reservadas a grupos de mayores ingresos. Otros ejemplos son el Conjunto Benito Juárez, las Unidades Santa Fe, Independencia, Kennedy y Nonoalco Tlatelolco.

Cabe aclarar que la oferta de vivienda social producida por el Estado nunca alcanzó a los sectores de menores recursos, beneficiando sobre todo a una clase media emergente de los años cincuenta que tuvo acceso por primera vez a condiciones de confort moderno (sanitario, agua caliente, estufa de gas, etc.). Graciela de Garay (2004) ha documentado y mostrado la satisfacción que comparten en la memoria colectiva sus primeros habitantes.

En la periferia de la ciudad y en los pueblos y villas que fueron absorbidos por el crecimiento urbano se identifica otra tipología de asentamiento irregular que es el resultado de la subdivisión de grandes lotes rurales, entre los miembros de una familia o en el peor de los casos en pequeñas parcelas sin ningún tipo de servicio, ofrecidas en alquiler a familias de escasos recursos y que fueron conocidas como ciudades perdidas. La precariedad característica de este tipo de asentamientos los hizo objeto de proyectos de reubicación en conjuntos habitacionales en los

18 Proyectado por Mario Pani, seguidor de los principios estéticos del urbanismo funcionalista signado por Le Corbusier. A la construcción del CUPA le siguieron otros complejos habitacionales emblemáticos de la modernidad arquitectónica, caracterizados por una separación tajante de los usos y actividades urbanas: vivienda, servicios y áreas verdes; por la organización del espacio habitable en supermanzanas e igualmente por la separación de los flujos de circulación urbana en vías jerarquizadas: peatonales, tránsito vehicular local, tránsito vehicular externo. 
que predomina la vivienda unifamiliar y que fueron construidos por el gobierno local. Dos ejemplos de esta tipología son las Unidades Santa Cruz Meyehualco y San Juan Aragón. También podían encontrarse grandes predios alquilados sin servicios de esta forma en colonias populares como la Guerrero o Morelos que se encontraban en el centro de la ciudad.

En 1972 se crearon los dos grandes fondos para el financiamiento de vivienda social que siguen operando hasta nuestros días: el Fovissste y el Infonavit, dedicados a atender la demanda de los trabajadores del sector público y privado respectivamente. Ambas instituciones produjeron miles de unidades de vivienda concentradas en grandes conjuntos habitacionales (Iztacalco, El Rosario, Culhuacan) que cumplían aun con ciertos criterios de calidad en su diseño y organización espacial. En la década de los ochenta la demanda social superaba los presupuestos mermados por la crisis económica, por lo que de manera paulatina se sacrificó calidad por cantidad. Se empezaron a construir unidades sin servicios vecinales, con espacios abiertos cada vez más reducidos y viviendas cada vez más pequeñas, de tal forma que este tipo de hábitat se convirtió en sinónimo de hacinamiento y problemáticas sociales.

En la década de los noventa el retiro progresivo del Estado como proveedor de vivienda social y prestador de servicios urbanos marcó el fin de los subsidios que habían permitido mantener a los conjuntos habitacionales funcionando. A partir de este momento y dependiendo de la capacidad de organización de los vecinos convertidos en copropietarios de áreas y servicios comunes, estos espacios habitacionales se han visto enfrentados a un deterioro progresivo por falta de mantenimiento, agravado por los conflictos vecinales.

De vuelta a la década de 1940, una vez que se saturó la oferta de cuartos redondos en las vecindades de la ciudad central y ante la incapacidad del mercado formal como de los programas institucionales para atender la creciente demanda de suelo y vivienda, las familias de menores recursos optaron por la adquisición de lotes en la periferia ofertados mediante distintos procedimientos en el mercado informal.

La propiedad ejidal, uno de los triunfos de los campesinos que participaron en la revolución, se convirtió en una reserva para el crecimiento de la ciudad informal, a veces recurriendo a las estrategias del corporativismo oficial, en otras mediante la ocupación ilegal del suelo por parte de organizaciones sociales disidentes. De esta manera entre 1940 y 1980 coincidieron en la periferia de la ciudad de México, los desalojos violentos de asentamientos irregulares, las invasiones masivas de tierras ejidales o de propiedad pública, con las reubicaciones en proyectos habitacionales emblemáticos de la modernidad arquitectónica y la emergencia de una crítica que ensalzaba la capacidad de los habitantes de escasos recursos para resolver el problema de la vivienda frente a la incapacidad de las autoridades rebasadas por la magnitud del problema y reducidas por la estrechez de los presupuestos gubernamentales. ${ }^{19}$

${ }^{19}$ Como ejemplo de las Instituciones se encuentra El Banco Mundial al cual el mismo John Turner llevó sus ideas para apoyar la autoconstrucción en ciudades latinoamericanas. Por su parte, la academia que estaba 
El caso paradigmático de este proceso son el conjunto de colonias que integraron la localidad de Ciudad Nezahualcoyotl al oriente de la zona metropolitana. Los primeros asentamientos irregulares de esta zona se remontan a 1933. En 1949, el presidente intervino para que los terrenos del Ex vaso del Lago de Texcoco fueran aprovechados con fines urbanos, lo que alentó la venta de lotes sin servicios por parte líderes comuneros del municipio de Chimalhuacán y de otros desarrolladores privados. En 1954 la población de del asentamiento sumaba más de cuarenta mil habitantes enfrentados a la carecían de servicios básicos y a la irregularidad de la propiedad que había sido el resultado de fraccionamientos ilegales y reventas fraudulentas. La precariedad forzó a la población cada vez más numerosa a organizarse en comités y asociaciones para reclamar la intervención de las autoridades federales y estatales. En 1963 se decretó la creación del municipio, lo que facilitó el establecimiento de bases institucionales locales para llevar a cabo un programa de regularización y reordenamiento de los asentamientos existentes. Al finalizar el siglo la población de Neza sumaba 1.5 millones de habitantes.

A partir del movimiento estudiantil de 1968, las organizaciones populares fueron ganando espacios alternativos en la lucha por el derecho a la vivienda frente a un Estado autoritario que ejercía el control a través del corporativismo institucionalizado y de las prácticas clientelares del partido oficial. La diáspora de activistas e intelectuales de izquierda que huían de las dictaduras militares en Sudamérica dio un impulso fundamental a estas organizaciones en México, y algunos pocos se sumaron a los estudios urbanos. ${ }^{20}$ La primera Conferencia de ONU-Habitat celebrada en Vancouver en 1976 institucionalizó el reconocimiento de la capacidad de los pobres urbanos para organizarse y resolver de forma autogestiva sus necesidades de vivienda, equipamiento y servicios, lo que derivó en programas de gobierno de apoyo a la autoconstrucción y a la organización de cooperativas de vivienda con financiamiento de organismos de cooperación internacional. Casos emblemáticos de este proceso son las cooperativas Guerrero, Palo Alto y El Molino.

En el mismo período, en un contexto de crecimiento demográfico acelerado, ocurrieron los casos más impresionantes de tomas de suelo o invasiones que explican el origen de colonias como el Pedregal de Santo Domingo, Padierna y otras colonias del Ajusco medio al sur de la ciudad.

La implantación del modelo neoliberal en la década siguiente significó la supresión de estos programas y el traslado de la responsabilidad de garantizar el derecho a la vivienda (nunca cumplido para todos) del Estado a la iniciativa privada, concretamente a grandes empresas constructoras de conjuntos masivos de vivienda de interés social en la periferia de la ciudades,

ligada a los distintos marxismos comprobaba el fracaso de la democracia capitalista con los mecanismos para sobrevivir a la pobreza urbana como la autoproducción de vivienda.

${ }^{20}$ A este respecto se puede mencionar a Alicia Ziccardi, René Coulomb o Priscilla Connolly, éstos últimos europeos que han contribuido enormemente a la academia desde una perspectiva crítica y propositiva con proyectos de investigación y participación ciudadana. 
cuyo deterioro y abandono constituyen hoy uno de los grandes temas de la agenda urbanística en México. ${ }^{21}$

Cabe agregar que a pesar de las iniciativas acumuladas en las últimas décadas, no se ha logrado garantizar el acceso a una vivienda digna y segura para todas las familias mexicanas. Persisten sectores de población cuyo nivel de ingreso familiar los excluye de la oferta de vivienda dentro del mercado formal, y que han recurrido a la experiencia histórica de los asentamientos irregulares y los procesos autogestivos en sus versiones más perversas y virtuosas. Es decir, el clientelismo por un lado y las experiencias alternativas del cooperativismo y la autogestión social por otro. Un ejemplo dentro de la zona metropolitana de la ciudad de México son los municipios de Chimalhuacán y Chicoloapan, en donde la población de escasos recursos, que ha protagonizado esta historia, sigue construyendo su vivienda en terrenos adquiridos dentro del mercado informal, como ocurría hace ochenta años en otras zonas de la ciudad. Se trata de una evidencia contundente de la continuidad de procesos históricos y del arraigo de procedimientos políticos y económicos de la informalidad.(VEGA, 2014).

\section{Colonias Populares de la Ciudad de México}

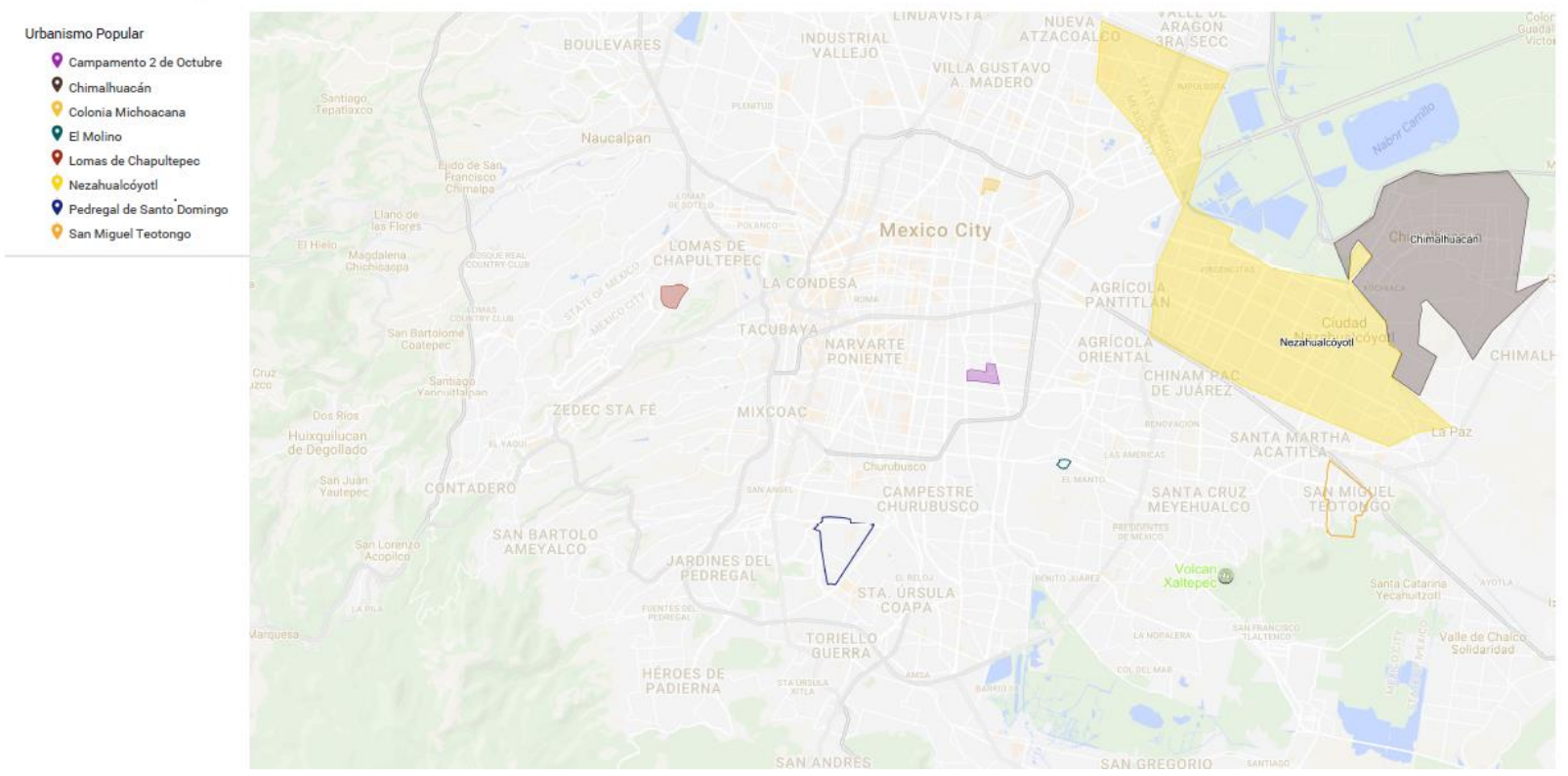

Fuente: elaboración propia.

Sobre los discursos y los agentes del urbanismo popular

Mediante el análisis de los procesos de urbanización popular se ha ido definiendo una trama compleja que conecta instituciones oficiales, organizaciones no gubernamentales, partidos políticos, grupos académicos y técnicos, organizaciones populares, comunidades y colectivos

21 El economista peruano Hernando de Soto, ha sido uno de los principales ideólogos neoliberales y promotores de la propiedad inmobiliaria como herramienta para superar la marginación histórica de los pobres en América latina, ya que el derecho a la propiedad privada es el medio para acceder al crédito. Estos postulados los desarrolla en su libro El misterio del capital (2000). 
ciudadanos (constituidos de manera formal o informal), con momentos de convergencia ideológica, rupturas y diálogo, en espacios institucionales o disidentes de escala local, nacional e internacional: desde asambleas comunitarias hasta los foros internacionales sobre vivienda, hábitat, ciudad etc.

En este sentido, el universo de estudio puede ser muy amplio, sin embargo en un esfuerzo de síntesis se reconoce una causa común que explica la convergencia de grupos y posturas muy diversas: la justicia social materializada en barrios y ciudades que deben favorecer el desarrollo pleno del ser humano.

En el período que hemos estudiado, se reconoce una evolución en el pensamiento de los agentes implicados. En los años sesenta los grupos de filiación anarquista o maoísta coincidían en su trabajo de campo con las comunidades eclesiales promovidas por miembros de la de iglesia católica afines a la teología de la liberación. El problema de los asentamientos irregulares era tan grande que permitió la coexistencia de espacios para el trabajo de grupos con posturas antagónicas en teoría, pero que en la práctica coincidían en la búsqueda de soluciones a la precariedad de los habitantes de los barrios marginales de las ciudades latinoamericanas.

Posteriormente la globalización, la implantación del modelo neoliberal y la crisis ambiental han ido moldeando los discursos. Coinciden nuevamente grupos heterogéneos en su lucha contra los efectos perversos de la apertura comercial, la desregulación de los mercados y el retiro del Estado de sectores estratégicos de la economía, como son la vivienda social y la dotación de servicios. Estos procesos coinciden con el fin de la etapa de crecimiento demográfico y urbano acelerado y el paso a un periodo de mayor estabilidad o incluso de decrecimiento. ${ }^{22}$

Desde los años sesenta, el impacto en el medio ambiente del crecimiento económico basado en la industrialización y los procesos de urbanización acelerados, comenzó a hacerse patente en la cotidianidad de sus habitantes. En la década de 1980 la ciudad de México se había convertido en un referente internacional de la degradación ambiental provocada por la devastación de los ecosistemas regionales y las concentraciones de contaminantes en la atmosfera.

Si bien, en un primer momento ciertas voces académicas identificaron a los pobres urbanos como agentes del deterioro ambiental, lo cierto es que los espacios de comunicación e intercambio que se fueron construyendo entre los agentes del urbanismo popular facilitaron la difusión de conceptos del ambientalismo científico y del marxismo ecológico ${ }^{23}$ y su traducción en

\footnotetext{
22 La ciudad central del área metropolitana de la ciudad de México comenzó a perder población desde la década de 1980. Esta situación se observa actualmente en sectores de la periferia que en su momento fueron emblemáticos de la urbanización informal en los años sesenta, como Ciudad Nezahualcoyotl.

${ }^{23} \mathrm{El}$ ambientalismo es un movimiento social en donde se configuran diversas líneas de pensamiento cuyo núcleo lo protagoniza la defensa del ambiente natural y humano, entendido éste, en el marco de la relación existente entre naturaleza y sociedad. El ambientalismo representa en sus muy diversos matices, movimientos en defensa del ambiente con mayor o menor relación con otras problemáticas sociales,
} 
proyectos y prácticas innovadoras como los huertos urbanos, el reciclaje de desechos sólidos o la aplicación de tecnologías verdes en la construcción de vivienda. En el trabajo de campo realizado en diversas comunidades autogestivas de la ciudad, sorprende la comunión de ideas entre sus líderes. Lo anterior gracias a la comunicación e intercambio posibilitado por los foros y asambleas que compartían dentro de su lucha política y en las últimas décadas reforzado con la construcción de redes sociales digitales.

Al igual que los conceptos y prácticas asociados a la protección y restauración del medio ambiente, se reconoce también la incorporación progresiva de otros discursos. En este sentido, el concepto de hábitat, ${ }^{24}$ a partir de la creación del consejo de la ONU respectivo en los años setenta, ha permitido integrar causas vinculadas con el medio ambiente natural y urbano. De esta manera las luchas ecologistas por los derechos de la naturaleza y las movilizaciones sociales de izquierda a favor de una vivienda, barrios y ciudades dignas se entrelazaron bajo este concepto "paraguas" integrador y al mismo tiempo ambiguo. Proceso equiparable al de los derechos humanos integrados bajo el derecho a la ciudad, que nos remite a la obra de Henri Lefebvre en los años sesenta, retomado y desarrollado posteriormente por David Harvey como el eje estructurador de una propuesta social frente a los embates del modelo urbano generado por el neoliberalismo.

\section{Reflexión final}

El urbanismo popular en este momento es una propuesta conceptual que reconoce la iniciativa, capacidad y experiencia de la población, generalmente de menores ingresos, para generar un hábitat urbano con sus propios recursos humanos y materiales en distintas escalas y con distintos grados de participación institucional. Permite explicar el origen y funcionamiento de la mayor proporción de las áreas urbanizadas en México.

Como hemos mencionado, alrededor del $50 \%$ de los espacios urbanizados de nuestras ciudades son el resultado de diversos procesos que englobamos en esta noción flexible de urbanismo popular, la cual incluye tanto los entornos construidos resultantes de procesos autogestivos, como aquellos generados desde la autoridad para atender las necesidades de la población de menores recursos, ambos derivan en tipologías cuyas características morfológicas específicas exigen un estudio más detallado.

Si bien, existen esfuerzos para comprender el fenómeno del urbanismo popular desde una perspectiva histórica, sigue pendiente la consolidación y diversificación de una historiografía especializada, equivalente al de los procesos formales de producción de entornos construidos y

económicas y políticas. De allí que existan enfoques ambientalistas más o menos afines con el antropocentrismo, ecocentrismo o biocentrismo (VÁZQUEZ, 2016).

24 Entendido como los entornos naturales y construidos que permiten el desarrollo de la vida $y$ concretamente en el caso de las ciudades, la satisfacción de las necesidades del ser humano. 
de otros períodos de la historia local. En este sentido, nos permitimos adelantar algunas explicaciones a estas carencias:

En un primer momento, los estigmas hacia la pobreza subyacentes en los círculos académicos más conservadores también han incidido en la indiferencia hacia este tipo de temáticas.

Por su contemporaneidad, la urbanización popular ha sido más bien objeto de estudio de las ciencias sociales, lo que explica la ausencia de historiadores profesionales especialistas en el tema. Cabe señalar, la influencia en su momento de la teoría del subdesarrollo que entendía la precariedad de los asentamientos populares como un estado transitorio en el camino hacia el desarrollo pleno. Este tipo de aproximaciones atizaron la discusión académica, la cual se intensificó con las transformaciones de la política económica de finales de los años setenta. Para el período de máxima expansión de las distintas formas de urbanización popular (1940-1980) existen numerosos estudios sobre vivienda popular y asentamientos precarios desde la perspectiva sociológica, antropológica, económica o del derecho, que pueden ser objeto de una relectura historiográfica.

Desde la historia de la arquitectura -que se ha encargado también de estudiar la historia del urbanismo institucional- la ausencia de grandes personajes hace poco atractivo este tema para los especialistas, que se enfrentan además a la escasez de registros documentales sobre la ocupación ilegal del suelo o la autoconstrucción, lo que dificulta el trabajo de investigación más convencional. De aquí la importancia de considerar otro tipo de fuentes documentales: orales y audiovisuales. Una perspectiva que ha sido poco explorada es la de la morfología urbana que privilegia el análisis de los entornos construidos como resultado de estructuras sociales, económicas y políticas.

Cada una de estas hipótesis requiere de un minucioso trabajo de investigación para ofrecer argumentos sólidos que permitan confirmarlas; labor que por sus dimensiones queda pendiente para futuros trabajos de investigación.

\section{Referencias}

AZUELA, Antonio; CRUZ, María Soledad. La institucionalización de las colonias populares y la política urbana en la ciudad de México (1940-1946. Sociológica. Revista del Departamento de Sociología, México, v. 9, n. 4, p.1-17, set. 1989.

BARRAGÁN, Pedro Moctezuma. La chispa.: Orígenes del Movimiento Urbano Popular en el Valle de México. México: Delegación Iztapalapa-para Leer En Libertad, 2012. 296 p. 
BARRAGÁN, Pedro Moctezuma. El movimiento urbano popular. Nueva Antropología, México, v. 6, n. 24, p.61-86, jan. 1984.

CONNOLLY, Priscilla. La ciudad y el hábitat popular: paradigma latinoamericano. In: SEMINARIO TEORÍAS SOBRE LA CIUDAD CONTEMPORÁNEA EN AMÉRICA LATINA, 9., 2011, México. Ponencia. México: Uam-x, 2011. p. 1 - 36. Disponível em: <http://www.ungs.edu.ar/catedrasur/wp-content/uploads/2012/11/12_CONNOLLY_VF.pdf>. Acesso em: 26 set. 2016.

CRUZ, María Soledad. Crecimiento Urbano y Procesos Sociales en el Distrito Federal. México: Uam-a, /. $201 \mathrm{p}$.

DUHAU, Emilio; GIGLIA, Angela. Las reglas del desorden.: Habitar la metrópoli. México: Siglo Xxi, 2008.

GARAY, Graciela (Comp.). Modernidad habitada: Multifamiliar Miguel Alemán, ciudad de México, 1949-1999. México: Instituto Mora, 2004.

GARZA, Gustavo. La Ciudad de México en el fin del segundo milenio. México: El Colegio de México-gobierno del Distrito Federal, 2000. 392 p.

LOT, A.; CAMARENA, P.. El Pedregal de San Ángel de la Ciudad de México: reserva ecológica urbana de la Universidad Nacional. In: LOT, A.; CANO-SANTANA, Z.. Biodiversidad del Pedregal de San Ángel. México: Unam-reserva Ecológica del Pedregal de San Ángelcoordinación de Investigación Científica, 2009. p. 19-25.

PACHECO, Sergio Miranda. La historia urbana en México.: Crítica de una historiografía inexistente. In: ROTHE, Héctor Quiroz; MAYA, Esther (Comp.). Urbanismo. Temas y tendencias. México: Unam, 2012. Cap. 11. p. 349-360.

RESEARCH IN PROGRESS ON URBAN HISTORY: Research in progress on urban History. Latin American Research Review: University Of Pittsburgh Press, v. 10, n. 2, 1991.

PERLÓ, Manuel. Estado, vivienda y estructura urbana en el cardenismo. México: Iis-unam, $1981.85 \mathrm{p}$. 
ROTHE, Héctor Quiroz (Comp.). Aproximaciones a la Historia del Urbanismo Popular. México: Unam, 2014. 396 p.

SÁNCHEZ-MEJORADA, María Cristina. Rezagos de la modernidad.: Memorias de una ciudad presente. México: Uam, 2005.

VAZQUEZ, Marina Laura Lanfranco. Diccionario virtual del Centro de Ciencia, Educación $y$ Sociedad (CECIES AC).Disponível em: <http://www.cecies.org/articulo.asp?id=145>. Acesso em: 26 set. 2016.

WARD, Peter. México: una megaciudad: Producción y reproducción de un medio ambiente urbano. México: Conaculta-alianza, 1991. 328 p.

Material Audiovisual

TESTIMONIOS para la historia del urbanismo popular en México. Capítulo 1. Direção de Héctor Quiroz Rothe. Produção de Unam. México: Unam, 2013. 1 (90 min.), DVD, son., color.

TESTIMONIOS para la historia del urbanismo popular en México. Capítulo 2. Direção de Héctor Quiroz Rothe. Produção de Unam. México: Unam, 2014. 1 (77 min.), DVD, son., color.

INTERIORES. Otra historia de la ciudad de México. Direção de Héctor Quiroz Rothe. Produção de Unam. México: Unam, 2015. 1 (62 min.), DVD, son., color.

Q.R. R. Quien Resulte Responsable. Direção de Gustavo Alatriste. Produção de Gustavo Alatriste. Realização de Gustavo Alatriste. Nezahualcóyotl, México: Gustavo Alatriste, 1970. 1 (110 min.), 35 mm, son., P\&B 